\title{
Value Added Products from Plant Processing
}

\author{
Abduvaly Jonmurodov', Jamshed Bobokalonov', Surayo Usmanova1, \\ Zayniddin Muhidinov ${ }^{1 *}$, Linshu Liu ${ }^{2 *}$ \\ ${ }^{1}$ Chemistry Institute of the Tajikistan Academy of Sciences, Dushanbe, Tajikistan \\ ${ }^{2}$ Eastern Regional Research Center ARS USDA, Wyndmoor, PA, USA \\ Email: ^muhidinovzayniddin@gmail.com, ${ }^{\star}$ linshu.liu@ars.usda.gov
}

How to cite this paper: Jonmurodov, A., Bobokalonov, J., Usmanova, S., Muhidinov, Z. and Liu, L.S. (2017) Value Added Products from Plant Processing. Agricultural Sciences, 8, 857-867. https://doi.org/10.4236/as.2017.88063

Received: July 7, 2017

Accepted: August 27, 2017

Published: August 30, 2017

Copyright () 2017 by authors and Scientific Research Publishing Inc. This work is licensed under the Creative Commons Attribution International License (CC BY 4.0).

http://creativecommons.org/licenses/by/4.0/

\section{(c) (i) Open Access}

\begin{abstract}
Fat and wax (F\&W) compounds have to be removed from raw plant materials before pectin and oligosaccharides (OS) can be isolated. In this research, the mixtures of $\mathrm{F} \& \mathrm{~W}$, and polyphenols and sugars were firstly separated from the roots of Eremurus hissaricus (Eremurus h.), and the byproducts of fruit processing, such as apple pomace, sunflower head residues, and grape seeds, etc., using hexane/ethanol or ethyl acetate as leaching reagents at various ratios of liquid to solid. The resultant mixtures were then extracted with an ethanol/water mixture to separate $\mathrm{F} \& \mathrm{~W}$ from polyphenols and sugars. It was found that the F\&W yield decreased in the sequence of apricot $>$ apple $>$ sunflower head residues $>$ peach $>$ pumpkin with $21.84 \%$ in apricot as the highest number. The amount of alcohol-water soluble compounds (AWSC), mainly polyphenols and sugars, decreased in the sequence of peach $>$ sunflower head residues $>$ apricot $>$ pumpkin $>$ apple. No inter-dependence of AWSC and F\&W was identified.
\end{abstract}

\section{Keywords}

Fats, Waxes, Pectin, Fruit Pomace, Sunflower Head, Grape Seedss, Grape

Cake, Eremurus hissaricus

\section{Introduction}

Before extracting pectin and oligosaccharides (OS) and other biologically active components from plant materials, the raw materials should undergo a defatting process in order to intensify the extraction and isolation processes. Fats and waxes have been used in various formulations for soap-making, skin and hair care, cooking and healing purposes. They give consistency and stability to body butters, healing balms, ointments, lip balms and creams. In addition, because waxes are not absorbed by the skin, they provide an outer layer of protection and 
a barrier against inclement weather, thereby also helping to retain moisture. Plant waxes embedded into the cuticle are called "intracuticular waxes", whereas waxes superimposed onto the cuticle are called "epicuticular waxes". Additional minor amounts of cutinized polysaccharide fiber, including cellulose and hemicellulose, and pectin, link the plant cuticle to the underlying cell wall [1]. Several properties of plant cuticles are mainly based on the waxes. Intracuticular waxes mainly function as water transpiration barriers [2], whereas epicuticular waxes strongly influence the wettability, self-cleaning behavior and the light reflection at the cuticle interface [3].

Plant waxes consist of a mixture of aliphatic hydrocarbons and their derivatives with carbon chain lengths between 20 atoms and 40 atoms, and in the case of esters (two connected chains) about 60 atoms. The main component classes are usually primary and secondary alcohols, ketones, fatty acids, and aldehydes. Alkanes are widely distributed but occur usually in low concentrations. However, many plant waxes do not match the chemical definition of true waxes. Triterpenoids, for example, occur in high concentrations in the epicuticular coatings of grapes. Other plant waxes contain polymeric components such as polymerized aldehydes which are only slightly soluble in chloroform. Furthermore, the waxes of conifer needles contain estolides, e.g. oligomeric hydroxy fatty acids [4]. The exudates of some ferns and angiosperms, in particular several members of the Primulaceae, are mainly composed of flavonoids and are termed farinose instead of waxes [5]. Recently an increasing number of publications have reported the discovery of new wax components. Thus, a long list of rare and uncommon ingredients is known, including methyl-branched aliphatics and molecules combining aliphatic and cyclic parts [6].

Several reviews have addressed the chemical composition of plant waxes [6] [7] [8], but it must be noticed, that nearly all existing data of the chemical composition was based on solvent-extracted waxes. These are mixtures of epicuticular and intracuticular waxes, which may be chemically different, as shown by Jetter et al. [9] for the waxes of Prunus laurocerasus and recently for the waxes of Taxus baccata [10]. By the development of more selective methods, it is now possible to analyze separately the intra- and epicuticular wax fractions to get a better understanding of the wax chemistry and even the molecular architecture of single epicuticular wax sculptures [11].

The natural wax on apple fruit contains about fifty individual components belonging to at least half a dozen chemical groups. Two major classes of chemicals are often found. The major cyclic component of apple fruit wax is called ursolic acid and is highly water repellent [12].

Application of F\&W isolation could effectively improving pectin yield and quality in the production technology and bring another valuable byproduct, which the aim of this work.

For this purpose, the isolation of plant waxes is performed either by dissolution in organic solvents or with mechanical methods. Most waxes are easily so- 
luble in organic solvents and are completely dissolved within a few seconds. Some waxes contain components, which are only slightly soluble in organic solvent at ambient temperatures, e.g. aldehydes in sugar cane, or triterpenoids in the wax layer on grapes. Such waxes need to be dissolved in warm chloroform and it may be necessary to verify whether they have been dissolved completely. The complete extraction of the intracuticular waxes may require several minutes. Generally, solvent-extracted waxes contain intracuticular waxes and can be contaminated by other organic solvent soluble components from inside the tissues [6].

This work combines a number of plant processing technologies, but only focused on a defatting technique applied to the different kinds of plant species: sunflower head residue, fruit wastes, roots of plants and grape seeds. For a quantitative wax extraction, the plant material, e.g. roots, seeds, fruits pulp or pomace are immersed in the solvent. The materials for defatting were then consequently used in pectin production and plant oligosaccharides and polyphenol extraction procedures.

\section{Materials and Methods}

\subsection{Materials}

Apricot, grape (Toify, Aleatico and Isabella), pumpkin, apple, and peach were harvested on season and purchased from local market (Dushanbe, Tajikistan). Sunflower head residues were obtained from seedless sunflower heads (Helianthus annuus, Avangard) that were harvested from a suburb of Dushanbe, Tajikistan).

Eremurus $h$. were planted, cultivated, and harvested by the employees of the Biological Station of the Institute of Botany and Plant Physiology and Genetics, Tajik Academy of Sciences, in 2015 in Syjahkuh Hill, Tajikistan.

All chemicals were from Sigma-Aldrich (Reachim, Russia) and used as it is.

\subsection{Isolation of Fats and Waxes from Fruit Wastes}

The isolation of F\&W from fruit wastes consisted of two steps. First, the fruit wastes were dried, $50 \mathrm{~g}$ for each were then mixed with $300 \mathrm{ml}$ hexane/alcohol $(3: 2, \mathrm{v} / \mathrm{v})$ in a Soxhlet extractor (Figure 1$)$, and fluxed at following setting:

\section{Extraction time: 5 hours}

Temperature of the water bath, $80^{\circ} \mathrm{C}$

Length of each refluxing cycle, $30 \mathrm{~min}$.

Number of cycle, 12

At the end of fluxing-leaching, the solvents were separated from the fruits wastes by filtration, and then evaporated to obtain a mixture of solid and semisolid residue, which were washed with ether for a few times, then dried in oven at $37^{\circ} \mathrm{C}$. The intermediates thus obtained were referred as total extracts that consist of fats, waxes, polyphenols and sugars compounds. 


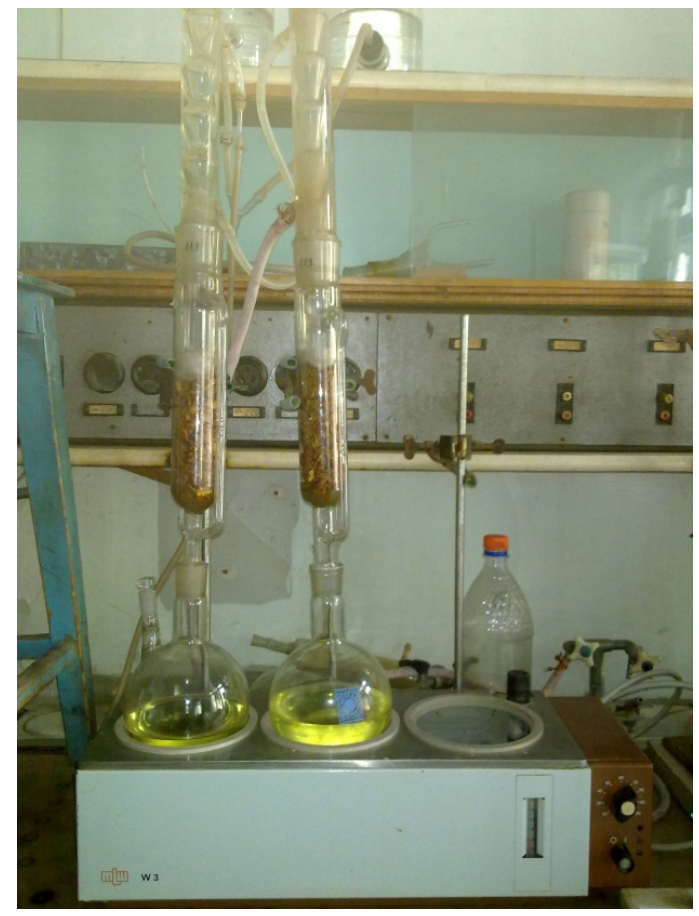

Figure 1. Soxhlet apparatus for extraction of F\&W, OS and phenols from plant raw materials.

In the second step, the solid phase was extracted with $10 \%$ alcohol-water solution to separate phenolic and sugar compounds in the liquid phase from F\&W in solid phase.

F\&W contents were calculated by subtracting the amounts of AWSC from the amounts of the total extractant.

\subsection{Extraction of Fats and Waxes from Roots of Eremurus $h$.}

The collected root tubers of the Eremurus $h$. were washed with tap water, dried at room temperature for one day. The dried root tubers $(500 \mathrm{~g})$ were cut, using a kitchen knife, into thin sheet-like pieces and spread out on filter paper and left to completely dry at $28^{\circ} \mathrm{C}-30^{\circ} \mathrm{C}$ for additional 10 days. The dried sheets were milled for 10 minutes in a laboratory mill (Retsch GM 200, Germany) to obtain fine powders. The powders were processed for separating F\&W, polyphenols and sugars compounds from the raw materials by the methods described above with slight modification:

Leaching reagent, ethyl acetate

Ratio between solid and liquid, $87.66 \mathrm{~g}: 750 \mathrm{ml}$

Length of a reflux cycle, 40 - $45 \mathrm{~min}$

\subsection{Extraction of Fats and Waxes from Grape Cake and Seeds}

F\&W and AWSC were separated from grape pomace (grape cake) and grape seeds from the grapes growing in three different locations in Tajikistan: Toify, 
Aleatico and Isabella. The grape pomace and seeds were dried at $40^{\circ} \mathrm{C}$, grounded to a particle sizes between $0.8-2.0 \mathrm{~mm}$. The extraction and separation were operated under the conditions similar to that used for Eremurus $h$. roots, except for 1) 12 - 14 refluxing cycles were applied for the extraction of fats, waxes, polyphenols, and sugars, and 2) the ratio of solid to liquid in extraction was 1:10, $\mathrm{w} / \mathrm{v}$.

\subsection{Characterization of Fats and Waxes by Fourier Transform Infrared Spectroscopy (FTIR)}

The F\&W sample were dried over glass slides to form films, which were analyzed by FT-IR spectroscopy using a Spectrum 65 FT-IR (Perkin Elmer) spectrometer equipped with MIRACLE ATR (ZNSE). Each recorded spectrum is the average of 16 scans in the range $4000-600 \mathrm{~cm}^{-1}$ with a $4 \mathrm{~cm}^{-1}$ resolution in transmission on a dried sample, with a background spectrum recorded before each analysis. Three spectra were taken and each one was analyzed and fitted using Perkin Elmer Spectrum, version 10.03.07 software. The shift in spectra in the repeat measurements performed on the same sample was about $2 \%$.

\section{Result and Discussion}

\subsection{Extraction of Fats, Waxes, Polyphenols, and Sugars from the Residues of Fruit Processing}

Extracts in hexane/ethanol were the mixtures of fats, waxes, polyphenols, and sugars. After removing the leaching reagents, the residues appeared as highly hygroscopic ointment-like materials, or viscous fluids, or powders, depending the types of the fruits. The time curves of extraction were shown in Figure 2.

For the residues from apple, peach and sunflower processing, the extraction peaks were recorded at around $1-1.5$ hours after the extraction is started that is much earlier than the record of $3^{\text {rd }}$ hour for pumpkin and apricot. The differences

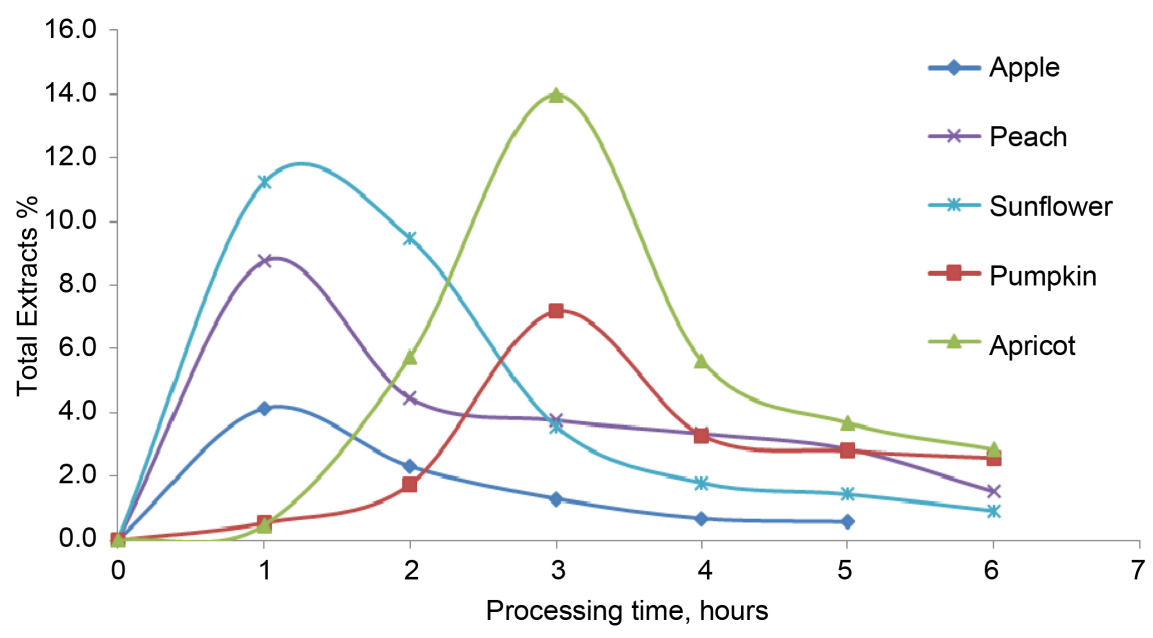

Figure 2. Time curve of total extracts in hexane/ethanol from the residues of fruit processing. 
could be attributed to the differences in solubility of fats, waxes, polyphenols, and sugars in the hexane/ethanol solution and their diffusion coefficient through cell walls to the environment.

Table 1 shows the yields of extracted materials from fruit wastes. The resulting $\mathrm{F} \& \mathrm{~W}$ yield in pumpkin was less in comparison to other studied fruits. F\&W quantities increased from pumpkin, peach, sunflower, apple to apricot. The quantities of AWSC isolated from total extracted materials increased as apple < to apricot $<$ pumpkin $<$ sunflower $<$ peach. No correlation between F\&W and AWSC contents were found.

The extraction kinetics also expressed as the time-dependence of weight loss of the raw materials. The typical curve was shown in Figure 3, using apple pomace as an example. Figure 3 illustrates a three-stage diffusion kinetics: the first hour was characterized with a sharp weight loss (weight loss, 6.3\%) followed by a retarding diffusion that lasted for 3 hours (weight loss, 3.5\%), and a slow mass diffusion period in the last 1 hour (weight lost, $0.2 \%$ ), reaching at a total weight loss of $10 \%$ in 5 hours. Such pattern of extraction was likely due to simultaneous isolation of a number of compounds in first hours of extraction having both hydrophobic and hydrophilic chains including phenols and sugar derivatives, which were further isolated from F\&W materials.

The F\&W occupied a big fraction of $80 \%$ of the total materials extracted from

Table 1. Yields of pectin, lipids and AWSC from different plant materials.

\begin{tabular}{ccccc}
\hline \multirow{2}{*}{ Plant materials } & \multicolumn{4}{c}{ Products yield, \% } \\
\cline { 2 - 5 } & Pectin & Total extracted materials & F\&W & AWSC \\
\hline Apricot & 6.00 & 32.34 & 21.84 & 10.50 \\
Sunflower & 22.00 & 28.44 & 15.04 & 13.40 \\
Peach & 8.00 & 24.70 & 13.15 & 14.55 \\
Pumpkin & 10.00 & 18.12 & 9.90 & 8.22 \\
Apple & 18.00 & 9.02 & 17.91 & 1.90 \\
\hline
\end{tabular}

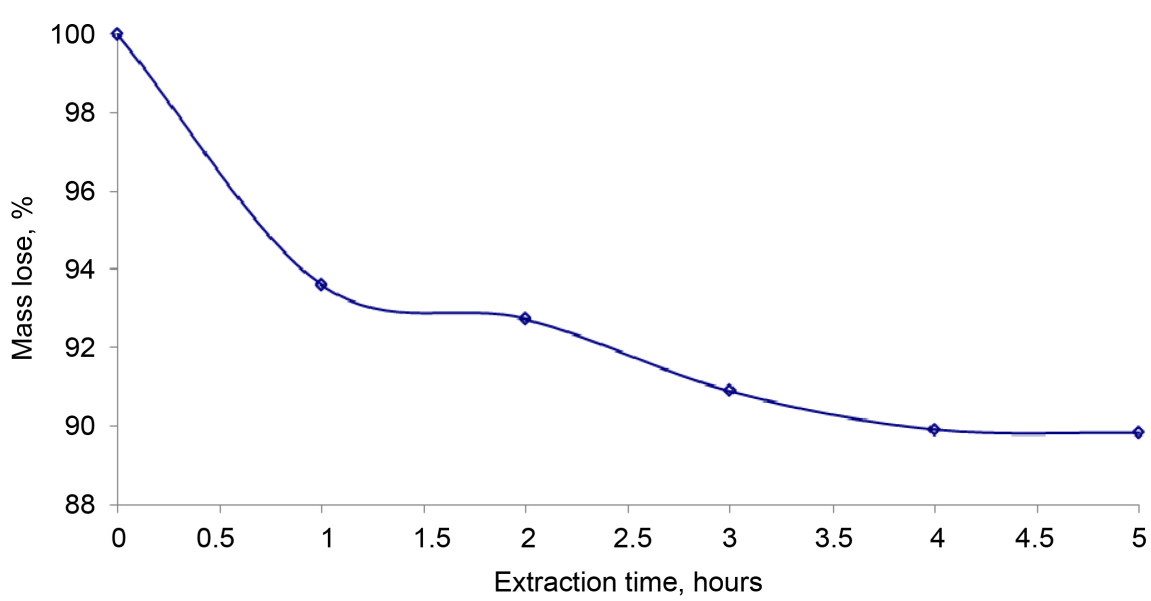

Figure 3. Apple pomace mass loss profile during batch extraction process. 
fruit wastes, or $8 \%$ of the total raw materials. The remaining $20 \%$ of the extracted materials in the leaching medium of hexane/ethanol mainly were polyphenols and sugar compounds. The trend line of $\mathrm{F} \& \mathrm{~W}$ isolation process perfectly fitted with first order diffusion process, and can be well described by the polynomial equation $\mathrm{y}=-0.3044 \mathrm{x}^{2}+3.0526 \mathrm{x}+0.2659$ with $\mathrm{R}^{2}=0.982$ (Figure 4).

\subsection{Extraction of Fats and Waxes from Eremurus $h$. and Grape Cake}

Eremurus is a genus of deciduous perennial flowers, also known as the foxtail lilies or desert candles [13]. Eremurus $h$. is a desert Asphodeloideae family plant growing in the mountain area in Central Asia. Eremurus is a plant native to the Tien Shan and Pamir Mountains in central Asia that is often used as an ornamental plant. The roots of the Eremurus $h$. at the fruiting stage were collected in October 2015 in Siyakah Biological Station, Tajikistan. Table 2 shows the amount of F\&W isolated from Eremurus $h$. roots together with the amount of F\&W from grape cakes and seeds, as described in the previous session, the same type of leaching reagent and extraction reagent were applied for $\mathrm{F} \& \mathrm{~W}$ isolation from these raw materials.

From the Table 2, it is visible that the amounts of extracted materials including F\&W were higher in grape seeds, and then decreased from the roots of

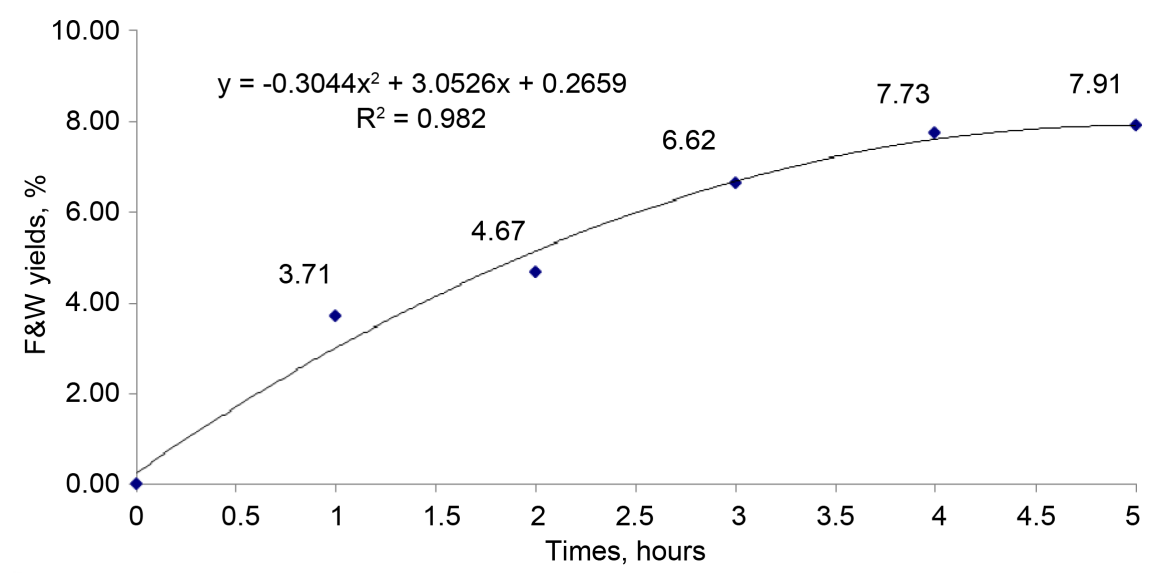

Figure 4. Cumulative F\&W yields on batch extraction duration from the apple pomace treated by hexane-alcohol mixture.

Table 2. The yields of F\&W substances from root of Eremurus $h$., grape cakes and seeds.

\begin{tabular}{cccc}
\hline Plant materials & $\begin{array}{c}\text { Plant material } \\
\text { initial mass, g. }\end{array}$ & $\begin{array}{c}\text { Quantity of isolated } \\
\text { F\&W, g }\end{array}$ & $\begin{array}{c}\text { Yields of } \\
\text { F\&W, \% }\end{array}$ \\
\hline Eremurus h. roots & 87.60 & 8.80 & 10.04 \\
Grape cake (Isabella) & 80.00 & 7.68 & 9.00 \\
Grape cake (Toify) & 80.00 & 5.30 & 6.62 \\
Grape cake (Aleatico) & 60.00 & 5.15 & 8.58 \\
Grape seeds (Isabella) & 60.00 & 9.58 & 15.97 \\
\hline
\end{tabular}


Eremurus $h$. to grape cakes from Isabella, Aleatico and Toify respectively. The defatted plant materials and isolated F\&W compounds have been used for further study to isolate phenolic substances. For this purpose, extracted solution was vacuum-evaporated to the minimal volume of $20-30 \mathrm{ml}$ and dried at the ambient temperature. The solid material then treated by $10 \%$ water solution of ethanol in order to isolate AWSC [14]. Table 3 shows the yields of AWSC of the grape cakes (Aleatico, Isabella, and Toify), grape seeds (Isabella), and Eremurus $h$. as determined by the Folin-Ciocalteu (FC) method [15]. Table 3 shows that the amount of polyphenols extracted from F\&W were higher in the grape cakes of Isabella than Aleatico. The content of phenolic substances as determined by the FC method was higher in the grape seeds then in the grape cakes. The study on phenolic compounds will be a subject of further work.

FT-IR spectra of the following F\&W components from: sunflower head residue, root of Eremurus $h$. in two growing phase and beeswax as a comparison sample [16] are studied. Figures 5(a)-(d) show that the beeswax and all studied samples have common bands: two intense bands at about 2917-2920, and 2848 $2851 \mathrm{~cm}^{-1}$, respectively, assigned to the asymmetric and symmetric stretching vibrations of methylene and methyl groups, a weak band at about $1736 \mathrm{~cm}^{-1}$ in all F\&W sample, except for that from sunflower head, due to the stretch of $\mathrm{C}=\mathrm{O}$ bond of ester groups. The very intense band about $1694 \mathrm{~cm}^{-1}$ indicate highly etherified caboxyl group of fatty acids in the sunflower waxes.

A weaker band at $1465 \mathrm{~cm}^{-1}$ and a very weak one at $721 \mathrm{~cm}^{-1}$, specific to compounds containing long aliphatic chains, slightly more intense for beeswax, and the band at about $1167 \mathrm{~cm}^{-1}$ attributed to $\mathrm{C}-\mathrm{O}-\mathrm{C}$ bonds, also more intense for beeswax.

It is clear from FTIR spectra of the Eremurus $h . \mathrm{F} \& \mathrm{~W}$ in budding phase (c) and fruiting phase (d), the in-tense bond form methyl groups at about $1736 \mathrm{~cm}^{-1}$ shift to the $1709 \mathrm{~cm}^{-1}$ and the difference of stretching of $\mathrm{C}=\mathrm{O}$ bond of carboxyl group of fatty acids shift from $1632 \mathrm{~cm}^{-1}$ to $1616 \mathrm{~cm}^{-1}$.

The above differences between the IR spectra of beeswax and studied F\&W samples of one plant species during growing phase may be considered as diversity in the chemical bonding of the F\&W components.

Table 3. The yields and polyphenols from root of Eremurus h., grape cakes and seeds.

\begin{tabular}{cccc}
\hline Plant materials & $\begin{array}{c}\text { Yields of } \\
\text { AWSC, } \% \\
\text { (from F\&W) }\end{array}$ & $\begin{array}{c}\text { Yields of AWSC, \% } \\
\text { (from plant) }\end{array}$ & $\begin{array}{c}\text { Total phenol content by } \\
\text { FC method, } \\
\left(\text { GAE }^{*} \mathrm{mg} / \mathrm{L}\right)\end{array}$ \\
\hline Eremurus h. roots & 3.78 & 0.32 & 114.12 \\
Grape cake (Isabella) & 28.35 & 1.43 & 314.04 \\
Grape cake (Toify) & 4.13 & 0.06 & 234.56 \\
Grape cake (Aleatico) & 11.34 & 0.82 & 345.65 \\
Grape seeds (Isabella) & 4.45 & 0.58 & 418.87 \\
\hline
\end{tabular}




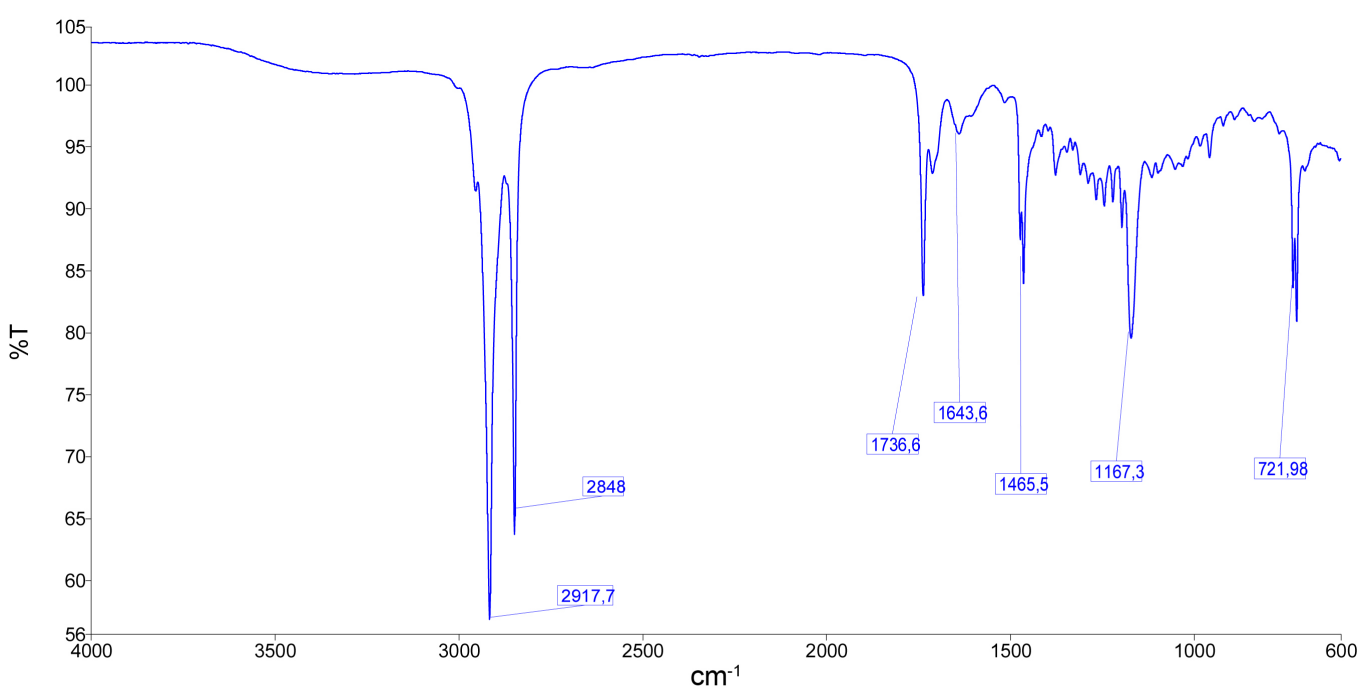

(a)

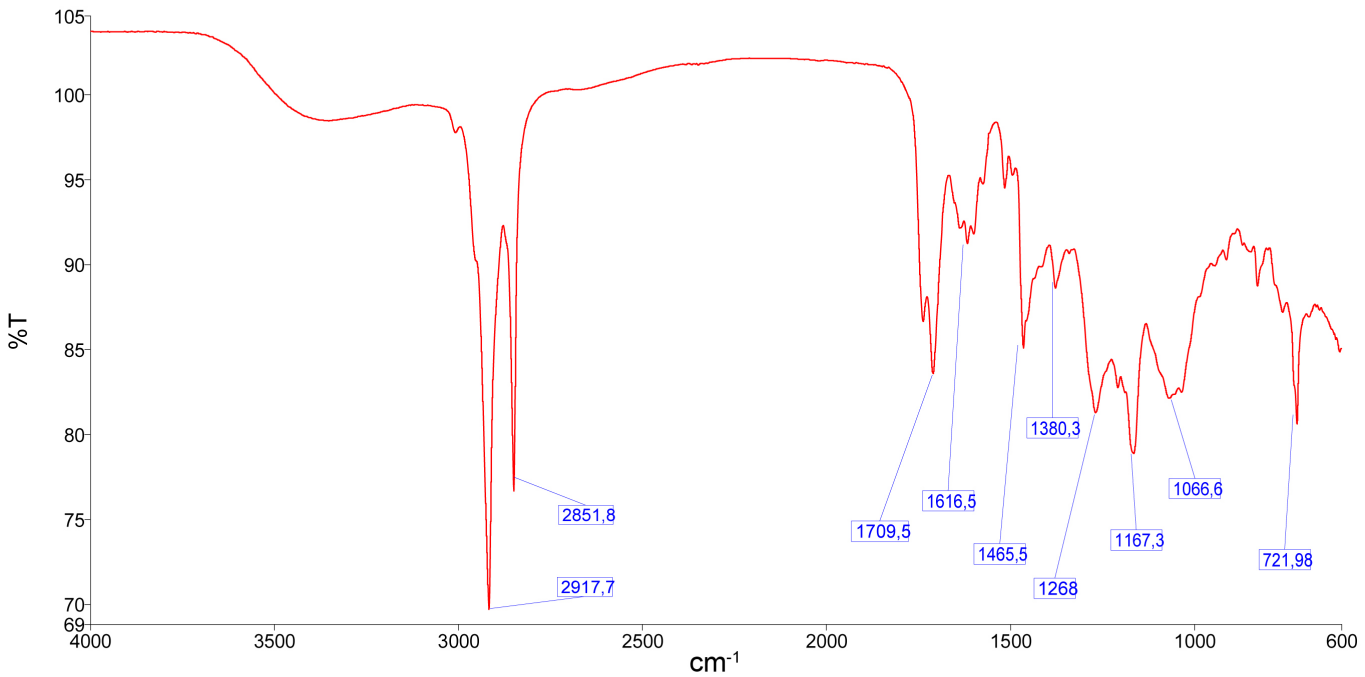

(b)

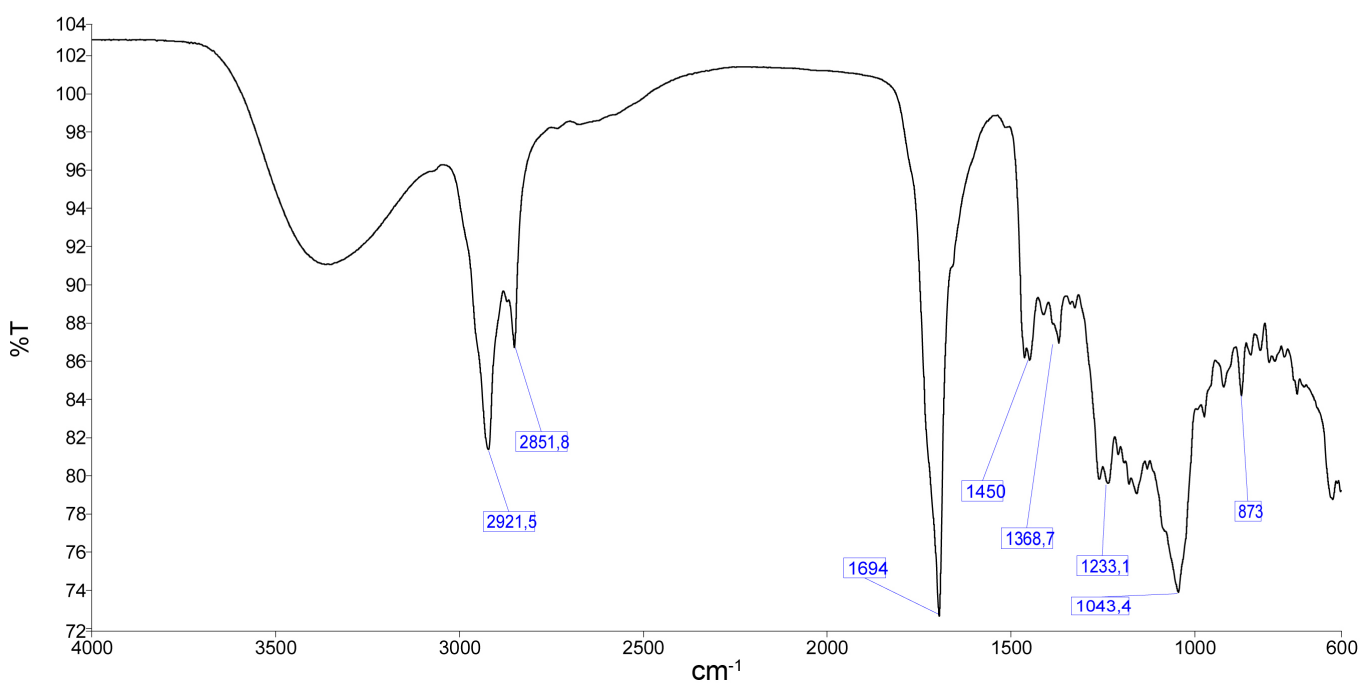

(c) 


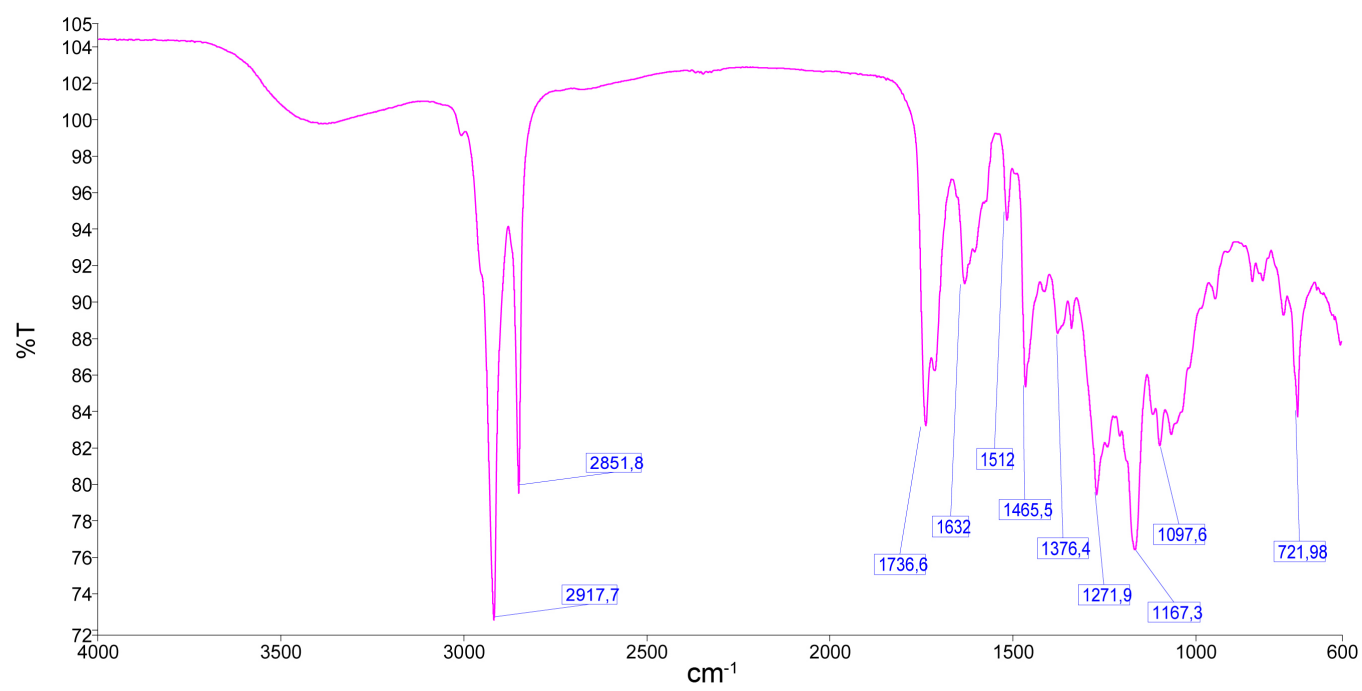

(d)

Figure 5. ATR FT-IR spectra of beeswax (a), sunflower head (b), Eremurus h. roots in budding phase (c) and fruiting phase $(\mathrm{d})$.

\section{Conclusion}

In this study, a defatting technique used an organic solvent applied to the different kind of plant species: fruit wastes, roots of plants and grape seeds. The resulting F\&W yields were higher in apricot fruit (22.5\%) in comparison with other studied plants. F\&W percentage yields decreased from apricot to grape cake (Aleatico). The quantity of AWSC isolated from the total extracted materials was lowest in apple then increased to peach. The grape cake (Isabella) has the highest content of AWSC. But, there was no correlation between F\&W and AWSC. FTIR spectra of three studied candidate samples indicate differences in structure of studied F\&W from well-known beeswax. Isolating F\&W would improve pectin yields. Thus, defatted materials would be used in pectin production and oligosaccharides and polyphenol extraction processing.

\section{Acknowledgements}

The ISTC T-2148 project, funded by the United States, is gratefully acknowledged for financial support. We are highly thankful to Ms. Wendy H. Kramer, M.L.S., Librarian, USDA, ARS, Eastern Regional Research Center, for editing.

\section{References}

[1] Holloway, P.J. (1994) Plant Cuticles: Physicochemical Characteristics and Biosynthesis. In: Percy, K.E., Cape, J.N., Jagels, R. and Simpson, C.J., Eds., Air Pollutants and the Leaf Cuticle. NATO ASI Series (Series G: Ecological Sciences), Springer, Berlin, Heidelberg, 36, 1-13. https://doi.org/10.1007/978-3-642-79081-2_1

[2] Riederer, M. and Schreiber, L. (1995) Waxes-The Transport Barriers of Plant Cuticles. In: Hamilton, R.J., Ed., Waxes. Chemistry, Molecular Biology and Functions, The Oily Press, West Ferry, Dundee, 6, 130-156.

[3] Bargel, H., Koch, K., Cerman, Z. and Neinhuis, C. (2006) Evans Review No. 3: 
Structure-Function Relationships of the Plant Cuticle and Cuticular Waxes-A Smart Material? Functional Plant Biology, 33, 893-910. https://doi.org/10.1071/FP06139

[4] Hamilton, R.J. (1995) Waxes: Chemistry, Molecular Biology and Functions. The Oily Press, Dundee, 349.

[5] Wollenweber, E. and Schneider, H. (2000) Lipophilic Exudates of PteridaceaeChemistry and Chemotaxonomy. Biochemical Systematics and Ecology, 28, 751777. https://doi.org/10.1016/S0305-1978(99)00118-0

[6] Jetter, R., Kunst, L. and Samuels, A.L. (2006) Composition of Plant Cuticular Waxes. In: Riederer, M. and Muller, C., Eds., Biology of the Plant Cuticle. Annual Plant Reviews 23, Blackwell Publishers, 145-175. https://doi.org/10.1002/9780470988718.ch4

[7] Kunst, L. and Samuels, A.L. (2003) Biosynthesis and Secretion of Plant Cuticular Wax. Progress in Lipid Research, 42, 51-80. https://doi.org/10.1016/S0163-7827(02)00045-0

[8] Baker, E.A. (1982) Chemistry and Morphology of Plant Epicuticular Waxes. In: Cutler, D.F., Alvin, K.L. and Price, C.E., Eds., The Plant Cuticle, Academic Press, London, 139-166.

[9] Jetter, R., Schaffer, S. and Riederer, M. (2000) Leaf Cuticular Waxes Are Arranged in Chemically and Mechanically Distinct Layers: Evidence from Prunus laurocerasus L. Plant, Cell \& Environment, 23, 619-628. https://doi.org/10.1046/j.1365-3040.2000.00581.x

[10] Wen, M., Buschhaus, C. and Jetter, R. (2006) Nanotubules on Plant Surfaces: Chemical Composition of Epicuticular Wax Crystals on Needles of Taxus baccata L. Phytochemistry, 67, 1808-1817. https://doi.org/10.1016/j.phytochem.2006.01.018

[11] Koch, K., Neinhuis, C., Ensikat, H.J. and Barthlott, W. (2004) Self Assembly of Epicuticular Waxes on Plant Surfaces Investigated by Atomic Force Microscopy (AFM). Journal of Experimental Botany, 55, 711-718. https://doi.org/10.1093/jxb/erh077

[12] Koch, K. and Ensikat, H.J. (2008) The Hydrophobic Coatings of Plant Surfaces: Epicuticular Wax Crystals and Their Morphologies, Crystallinity and Molecular SelfAssembly. Micron, 39, 759-772. https://doi.org/10.1016/j.micron.2007.11.010

[13] Wikipedia (2017) Eremurus. https://en.wikipedia.org/wiki/Eremurus

[14] Shi, J., Nawaz, H., Pohorly, J., Mittal, G., Kakuda, Y. and Jiang, Y. (2005) Extraction of Polyphenolics from Plant Material for Functional Foods-Engineering and Technology. Food Reviews Internationa, 21, 139-166. https://doi.org/10.1081/FRI-200040606

[15] Fuleki, T. and Francis, F.J. (1968) Quantitative Methods for Anthocyanins. II. Determination of Total Anthocyanin and Degradation Index for Cranberry Juice. Journal of Food Science, 33, 78-83. https://doi.org/10.1111/j.1365-2621.1968.tb00888.x

[16] ATR-FT-IR Spectrum of Beeswax (4000-225 cm-1). http://lisa.chem.ut.ee/IR_spectra/paint/binders/beeswax/ 
Submit or recommend next manuscript to SCIRP and we will provide best service for you:

Accepting pre-submission inquiries through Email, Facebook, LinkedIn, Twitter, etc. A wide selection of journals (inclusive of 9 subjects, more than 200 journals)

Providing 24-hour high-quality service

User-friendly online submission system

Fair and swift peer-review system

Efficient typesetting and proofreading procedure

Display of the result of downloads and visits, as well as the number of cited articles Maximum dissemination of your research work

Submit your manuscript at: http://papersubmission.scirp.org/

Or contact as@scirp.org 